\title{
Type 2 diabetes: postprandial hyperglycemia and increased cardiovascular risk
}

REVIEW

\author{
This article was published in the following Dove Press journal: \\ Vascular Health and Risk Management \\ 5 March 2010 \\ Number of times this article has been viewed
}

\section{Ajikumar V Aryangat John E Gerich}

University of Rochester, Rochester, New York, USA
Correspondence: John E Gerich University of Rochester Medical Center General Clinical Research Center, 60I Elmwood Avenue, Box MED/CRC, Rochester, New York 14642, USA Tel + I (585) 275-5295

Fax +I (585) 46I-4737

Email johngerich@compuserve.com
Abstract: Hyperglycemia is a major risk factor for both the microvascular and macrovascular complications in patients with type 2 diabetes. This review summarizes the cardiovascular results of large outcomes trials in diabetes and presents new evidence on the role of hyperglycemia, with particular emphasis on postprandial hyperglycemia, in adverse cardiovascular outcomes in patients with type 2 diabetes. Treatment options, including the new dipeptidyl peptidase-4 inhibitors and glucagon-like peptide-1 mimetics that primarily target postprandial hyperglycemia, are also discussed. Hyperglycemia increases cardiovascular mortality, and reducing hyperglycemia lowers cardiovascular risk parameters. Control of both fasting and postprandial hyperglycemia is necessary to achieve optimal glycated hemoglobin control. Therefore, antihyperglycemic agents that preferentially target postprandial hyperglycemia, along with those that preferentially target fasting hyperglycemia, are strongly suggested to optimize individual diabetes treatment strategies and reduce complications.

Keywords: postprandial hyperglycemia, diabetes mellitus, drugs, cardiovascular risk

\section{Introduction}

Several landmark clinical trials have convincingly demonstrated that hyperglycemia is associated with the microvascular complications of diabetes. ${ }^{1-3}$ These trials, along with epidemiological evidence, have provided the basis for treatment targets and algorithms recommended by the American Diabetes Association (ADA), the American Association of Clinical Endocrinologists (AACE), and the European Association for the Study of Diabetes (EASD). ${ }^{46}$ Adequacy of glycemic control is almost universally assessed by glycated hemoglobin $\left(\mathrm{HbA}_{1 \mathrm{c}}\right)$ - a measure of hemoglobin glycation over the erythrocyte life span that is proportional to the mean plasma glucose level over the preceding 2 to 3 months. An $\mathrm{HbA}_{1 \mathrm{c}}<7 \%$ is recommended by the ADA/EASD and $\leq 6.5 \%$ by the AACE. ${ }^{4-6}$ The mean value for individuals with normal glucose tolerance is $5.0 \%$ (upper limit of normal is $6.0 \%)$. $\mathrm{HbA}_{1 \mathrm{c}}$ can be communicated with patients using estimated average glucose (eAG; $\left.\mathrm{HbA}_{1 \mathrm{c}} 5 \%=\mathrm{eAG} 5.4 \mathrm{mmol} / \mathrm{L}, 97 \mathrm{mg} / \mathrm{dL}\right)$, so that they better understand how their blood glucose monitor readings are related to $\mathrm{HbA}_{1 \mathrm{c}}{ }^{4}{ }^{4}$

In addition to $\mathrm{HbA}_{1 \mathrm{c}}$, patients and physicians usually monitor and treat fasting plasma glucose (FPG) levels, but ignore or de-emphasize postprandial glucose (PPG) levels. There is no evidence that fasting hyperglycemia is more deleterious than postprandial hyperglycemia. Recent evidence, however, strongly suggests that control of postprandial hyperglycemia may be necessary to achieve $\mathrm{HbA}_{1 \mathrm{c}}$ targets $<7 \%$. ${ }^{7}$ Considerable data have accumulated indicating that elevated PPG levels, even in the absence of fasting hyperglycemia, increase the risk for cardiovascular (CV) disease (CVD). This article 
discusses and updates epidemiological and experimental studies linking postprandial hyperglycemia to CVD, and therapeutic approaches, both available and in development.

\section{Hyperglycemia and CVD}

In people with type 2 diabetes, macrovascular disease, in particular CVD, is the major source of morbidity and mortality. The pathogenesis of CVD is complex and multifactorial. Smoking, obesity, dyslipidemia, and hypertension were considered the major "traditional" risk factors. Now diabetes itself is considered an important independent risk factor. ${ }^{8}$ Having diabetes increases the risk for CVD mortality more than two-fold. ${ }^{9}$ For example, in the INTERHEART study, a case-control study that assessed risk factors of coronary artery disease (CAD) worldwide in nearly 30,000 subjects, diabetes increased the odds ratio of having an acute myocardial infarction (MI) to 4.26 (99\% confidence interval [CI], 3.51 to 5.18 ) in women and to 2.67 (99\% CI, 2.36 to 3.02 ) in men (Table 1), making diabetes as important a risk factor as smoking, hypertension, obesity, and dyslipidemia. ${ }^{10}$

Numerous epidemiological studies have demonstrated a correlation between risk for CVD and plasma glucose levels (both fasting and postprandial) or $\mathrm{HbA}_{1 \mathrm{c}}$ values. ${ }^{11}$ The relationship between PPG and CV events persists even in the context of $\mathrm{HbA}_{1 \mathrm{c}}$ levels in the nondiabetic range. ${ }^{11,12}$ Moreover, the Funagata Diabetes Study showed that the cumulative survival rates from CVD of impaired glucose tolerance (IGT) and diabetes were reduced comparably, whereas the cumulative survival rate from CVD of impaired fasting glucose (IFG)

Table I Association of risk factors with acute myocardial infarction in men and women

\begin{tabular}{lll}
\hline Risk factor & Sex & Odds ratio $(99 \% \mathrm{CI})^{\mathrm{a}}$ \\
\hline Diabetes & F & $4.26(3.5 \mathrm{I}-5.18)$ \\
Hypertension & M & $2.67(2.36-3.02)$ \\
Current smoking & F & $2.95(2.57-3.39)$ \\
& M & $2.32(2.12-2.53)$ \\
Abdominal obesity & F & $2.86(2.36-3.48)$ \\
& M & $3.05(2.78-3.33)$ \\
ApoB/ApoAI ratio & F & $2.26(1.90-2.68)$ \\
& M & $2.24(2.03-2.47)$ \\
\hline Ad & F & $4.42(3.43-5.70)$ \\
\hline
\end{tabular}

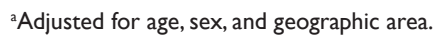

${ }^{\mathrm{b}} \mathrm{ApoB} / \mathrm{ApoA} \mathrm{I}$ ratio as an index of dyslipidemia.

Adapted from The Lancet, 364, Yusuf S, Hawken S, Ôunpuu S, et al; for the INTERHEART Study Investigators. Effect of potentially modifiable risk factors associated with myocardial infarction in 52 countries (the INTERHEART study): case-control study, 937-952. ${ }^{10}$ Copyright (C) (2004), with permission from Elsevier.

Abbreviations: F, female; $M$, male. was not. ${ }^{13}$ This suggests that IGT (or postprandial glycemia) is a more important CVD risk factor than IFG.

Epidemiological data suggest a strong link between $\mathrm{CV}$ risk and glucose control, but by nature of study design, cannot determine causality. Controlled clinical trials can determine causality and have examined the effects of glycemic control on vascular complications. The United Kingdom Prospective Diabetes Study (UKPDS), ${ }^{1}$ the Diabetes Control and Complications Trial (DCCT), ${ }^{3}$ the Action to Control Cardiovascular Risk in Diabetes (ACCORD),${ }^{14}$ and the Action in Diabetes and Vascular Disease: Preterax and Diamicron Modified Release Controlled Evaluation (ADVANCE) ${ }^{2}$ were landmark controlled clinical trials that evaluated the benefits of intensive glucose control on diabetes complications. The UKPDS demonstrated a $25 \%$ risk reduction for microvascular complications $(P=0.0099)$ and a $16 \%$ risk reduction for MI $(P=0.052)$ in intensively treated patients. ${ }^{1}$ Moreover, during a 10-year poststudy monitoring period, the UKPDS follow-up data demonstrated a persistent $15 \%$ risk reduction for $\mathrm{MI}$ $(P=0.01)$ and a $13 \%$ risk reduction for all-cause mortality $(P=0.007$; Figure 1$)$ despite a convergence in glycemic control levels between treatment groups. ${ }^{15}$

The DCCT follow-up study yielded a similar finding. The DCCT consisted of 1441 patients with type 1 diabetes randomized to intensive or conventional therapy for a mean of 6.5 years - 1983 through 1993.,16 Ninety-three percent of patients from the DCCT were followed until February 1, 2005, (mean 17-year follow-up) in the observational Epidemiology of Diabetes Interventions and Complications (EDIC) study. Intensive treatment reduced the risk of any CVD event by $42 \%(95 \% \mathrm{CI}, 9 \%$ to $63 \% ; P=0.02)$ and the risk of nonfatal MI, stroke, or death from CVD by $57 \%$ (95\% CI, $12 \%$ to $79 \% ; P=0.02$ ).

The ACCORD ${ }^{14}$ and ADVANCE ${ }^{2}$ trials evaluated intensive blood glucose control below the current recommended levels of $\mathrm{HbA}_{1 \mathrm{c}}$ and its impact on $\mathrm{CV}$ events. The ACCORD study consisted of 10,251 patients with type 2 diabetes with a median baseline $\mathrm{HbA}_{1 \mathrm{c}}$ of $8.1 \%$ who were given intensive therapy to target $\mathrm{HbA}_{1 \mathrm{c}}$ below $6 \%$ versus standard therapy $\left(\mathrm{HbA}_{1 \mathrm{c}}=7.0 \%\right.$ to $\left.7.9 \%\right)$. Thirty-five percent of patients had history of a previous CV event. The intensively treated arm of the study was terminated early because of higher mortality of 257 patients in this treatment group versus 203 patients in the standard therapy group. However, nonfatal MI occurred less often in the intensive group than in the standard group $(P=0.004)$. Although overall difference in macrovascular events in ACCORD was not statistically significant between intensive and standard therapy, patients in the intensive 


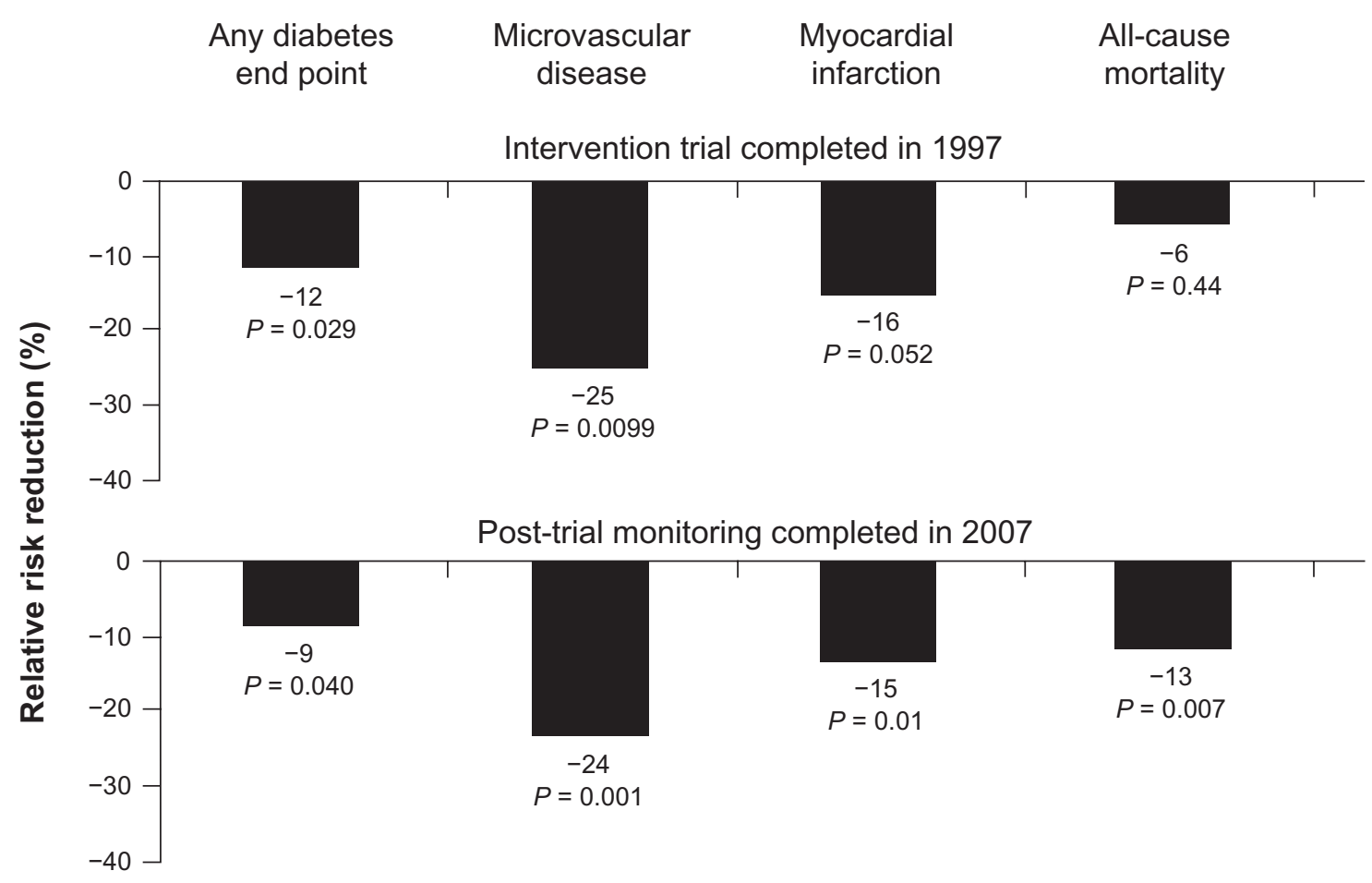

Figure I Significant relative risk reduction in microvascular disease and any diabetes end point continued during 10 years of post-trial follow-up. Significant emergent risk reductions in myocardial infarction and all-cause mortality were observed only with extended follow-up. ${ }^{1,15}$

Adapted from The Lancet, 352, UK Prospective Diabetes Study (UKPDS) Group, Intensive blood-glucose control with sulphonylureas or insulin compared with conventional treatment and risk of complications in patients with type 2 diabetes (UKPDS 33), 837-853.' Copyright (C) (1998), with permission from Elsevier.

therapy arm with no history of prior CV events or whose baseline $\mathrm{HbA}_{1 \mathrm{c}}$ level was $\leq 8 \%$ had significantly fewer fatal or nonfatal $\mathrm{CV}$ events than the standard therapy arm. In these subgroups, intensive lowering of $\mathrm{HbA}_{1 \mathrm{c}}$ was beneficial. ${ }^{14}$

The ADVANCE trial ${ }^{2}$ studied 11,140 patients with type 2 diabetes randomized to receive standard therapy or gliclazide plus other medications to achieve $\mathrm{HbA}_{1 \mathrm{c}}$ of $\leq 6.5 \%$ in the intensive control arm. With a median 5-year follow-up, mean $\mathrm{HbA}_{1 \mathrm{c}}$ was lower in the intensive control group (6.5\%) than in the standard control group (7.3\%). Intensive control reduced the incidence of combined major macro- and microvascular events $(18.1 \%$ versus $20.0 \%$ with standard control; hazard ratio [HR], $0.90 ; 95 \% \mathrm{CI}, 0.82$ to $0.98 ; P=0.01$ ), as well as that of major microvascular events $(9.4 \%$ versus $10.9 \%$; HR, 0.86 ; $95 \% \mathrm{CI}, 0.77$ to $0.97 ; P=0.01)$, primarily because of a reduction in the incidence of nephropathy $(4.1 \%$ versus $5.2 \%$; HR, $0.79 ; 95 \% \mathrm{CI}, 0.66$ to $0.93 ; P=0.006)$. The ADVANCE trial, while positive for microvascular complications, had an event rate too low to have the statistical power to show a benefit of intensive glucose control on macrovascular complications.

The Veterans Affairs Diabetes Trial (VADT) ${ }^{17}$ randomized 1791 patients with type 2 diabetes who had suboptimal control on oral medications or insulin with a median $\mathrm{HbA}_{1 \mathrm{c}}$ of $8.4 \%$ for intensive glucose control or standard therapy, with a goal of an absolute reduction of $1.5 \% \mathrm{HbA}_{1 \mathrm{c}}$ in the intensive versus standard therapy group. A major $\mathrm{CV}$ event, the primary outcome, occurred in 264 patients in the standard therapy group and 235 patients in the intensive therapy group (HR in the intensive therapy group, $0.88 ; 95 \% \mathrm{CI}, 0.74$ to 1.05 ; $P=0.14)$. The incidence of primary outcome was not significantly lower in the intensive arm, but a subgroup analysis indicated that patients who had diabetes less than $\sim 12$ years derived CV benefit from intensive glycemic control. ${ }^{18}$ Also, an embedded ancillary study within the main VADT showed that patients with previous history of increased baseline coronary or aortic calcium scores benefited less compared with patients who had low calcium scores. ${ }^{18}$

Together, the ACCORD, ${ }^{14}$ ADVANCE $^{2}$ and $\operatorname{VADT}^{17}$ studies showed significant $\mathrm{CV}$ benefit in patients who had lower baseline $\mathrm{HbA}_{1 \mathrm{c}}$, no prior history of $\mathrm{CAD}$, and shorter history of diabetes. Both the DCCT and UKPDS primary intervention studies also demonstrated long-term macrovascular benefits ( $>10$ year follow-up). ${ }^{15,16}$ Taken together, these studies illustrate that intensive glycemic control early in the course of diabetes is important in achieving CV benefit and provides guidance in terms of stratification of patients' target glycemic control. Thus, achieving a goal of $\mathrm{HbA}_{1 \mathrm{c}}<7 \%$ is recommended, but a less intense target should be planned for 
patients with history of severe CVD, severe hypoglycemia, or advanced microvascular or macrovascular disease complications. In addition to addressing diabetes control, physicians must optimize other modifying factors of CVD, including blood pressure, hyperlipidemia, obesity, smoking cessation, regular exercise, and healthy diet. ${ }^{18}$ In the future, development of a risk profile and stratification will be important in customizing and guiding each patient's glycemic target and optimizing the benefits of intensive glucose control.

\section{Mechanisms of hyperglycemia- induced CV damage}

Acute hyperglycemia has been linked to endothelial dysfunction. Monnier et $\mathrm{al}^{19}$ reported that the urinary excretion rate of 8-iso-prostaglandin $\mathrm{F}_{2 \alpha}$, a marker of oxidative stress, correlated best with the glycemic variability assessed from the mean amplitude of glycemic excursions. To add another level of complexity, Ceriello et $\mathrm{al}^{20}$ showed that not only was hyperglycemia associated with endothelial dysfunction in patients with and without type 2 diabetes, but also that oscillating glucose levels in 6-hour increments led to even greater dysfunction over time. Other studies also provided evidence that postprandial fluctuations, in addition to absolute increases in glycemia, contribute to oxidative stress and endothelial dysfunction. ${ }^{21-23}$ Endothelial dysfunction seems to be affected via the vascular glycocalyx (an extracellular matrix of endothelial cell-derived proteoglycans, glycoproteins, and absorbed plasma proteins that act as a mechanosensor/mechanotransducer of blood flow and vascular shear stress) in a predominantly nitric oxide-dependent manner that promotes endothelial response to stimuli. ${ }^{24-26}$ Nieuwdorp et $\mathrm{al}^{26}$ utilized several techniques (eg, hyperglycemic clamp, flow-mediated dilation, glycocalyx tracers, and laboratory analytical tests) to assess endothelial function and coagulation parameters after hyperglycemic challenge in 10 healthy males. After glucose infusion, glycocalyx volume was decreased, mechanotransduction of flow-dependent arterial dilation was attenuated, and levels of prothrombin activation fragment $\mathrm{F} 1+2$, a factor that initiates coagulation cascades, were increased during hyperglycemia. Moreover, reducing $\mathrm{PPG}$ has been reported to improve endothelial dysfunction. ${ }^{23}$ Oxidative stress caused by acute PPG spikes can contribute to macrovascular damage through oxidation of low-density lipoprotein, exacerbation of endothelial dysfunction, and other proatherogenic mechanisms. An overview of the complex interaction between factors that contribute to macrovascular complications of diabetes is presented in Figure 2. ${ }^{11,27}$

\section{Management of postprandial hyperglycemia}

Postprandial glucose control is the rate-limiting step when optimizing blood glucose levels, as demonstrated in the study by Woerle et al. ${ }^{7}$ This prospective interventional trial assessed the relative contributions of FPG and PPG in achieving recommended $\mathrm{HbA}_{1 \mathrm{c}}$ goals. There were 164 patients with type 2 diabetes with $\mathrm{HbA}_{1 \mathrm{c}}$ levels $>7.5 \%$ (mean $8.7 \% \pm 0.1$ ) with target reductions of FPG to $\leq 5.6 \mathrm{mmol} / \mathrm{L}(\leq 100 \mathrm{mg} / \mathrm{dL})$ and PPG at 90 minutes to $\leq 7.8 \mathrm{mmol} / \mathrm{L}(\leq 140 \mathrm{mg} / \mathrm{dL})$. The study showed that when FPG (but not PPG) was at target, only $64 \%$ of patients achieved $\mathrm{HbA}_{1 \mathrm{c}} \leq 7 \%$, whereas when both FPG and PPG were at target, 94\% achieved $\mathrm{HbA}_{1 \mathrm{c}} \leq 7 \%$. FPG values did not differ in patients with $\mathrm{HbA}_{1 \mathrm{c}}$ above or below 7\%. PPG accounted for $\sim 90 \%$ of $\mathrm{HbA}_{1 \mathrm{c}}$ values when $\mathrm{HbA}_{1 \mathrm{c}}$ was $<6.2 \%$, but only $\sim 40 \%$ when $\mathrm{HbA}_{1 \mathrm{c}}$ was $>8.9 \% .{ }^{7}$ These results further illustrate the importance of PPG in achieving better control of diabetes, consistent with an earlier study conducted by Monnier et al. ${ }^{28}$ Most recently, results from the 4-T trial (Treating to Target in Type 2 Diabetes) indicated preprandial treatment with a rapid-acting insulin analogue resulting in significant decreases in PPG $(-85 \pm 59 \mathrm{mg} / \mathrm{dL})$ compared with basal and biphasic insulin regimens $(-61 \pm 58 \mathrm{mg} / \mathrm{dL}$ and $-67 \pm 50 \mathrm{mg} / \mathrm{dL}$, respectively). ${ }^{29}$ However, while preprandial treatment with a rapid-acting insulin analogue resulted in significant reductions in $\mathrm{HbA}_{1 \mathrm{c}}$ from baseline $(-1.4 \% \pm 0.1)$, comparisons with basal and biphasic insulin regimens were not significantly different $(-1.3 \% \pm 0.1$ and $-1.2 \% \pm 0.1$, respectively). It is interesting to note that no differences were found in FPG levels among the treatment groups. ${ }^{29}$

Furthermore, randomized controlled trials with agents that primarily target postprandial hyperglycemia have demonstrated CV benefit. The Study to Prevent NonInsulin-Dependent Diabetes Mellitus (STOP-NIDDM) Trial showed that treating postprandial hyperglycemia with acarbose in patients with IGT reduced CV events. ${ }^{30}$ PPG levels seen in diabetic patients correlate with carotid intima-media thickness (CIMT), ${ }^{31}$ and treatment with antihyperglycemic agents such as nateglinide and acarbose - which target postprandial glycemia - reduces progression of CIMT. ${ }^{32,33}$ In addition, optimal control of postprandial hyperglycemia has been associated with improved coronary blood flow ${ }^{34}$ as well as possible reversal of myocardial perfusion abnormalities. ${ }^{35}$

\section{ADA, IDF, and AACE recommendations}

The ADA in its Standards of Medical Care in Diabetes-20094 acknowledges that elevated PPG values are associated with increased $\mathrm{CV}$ risk - independent of FPG - and that the relative 


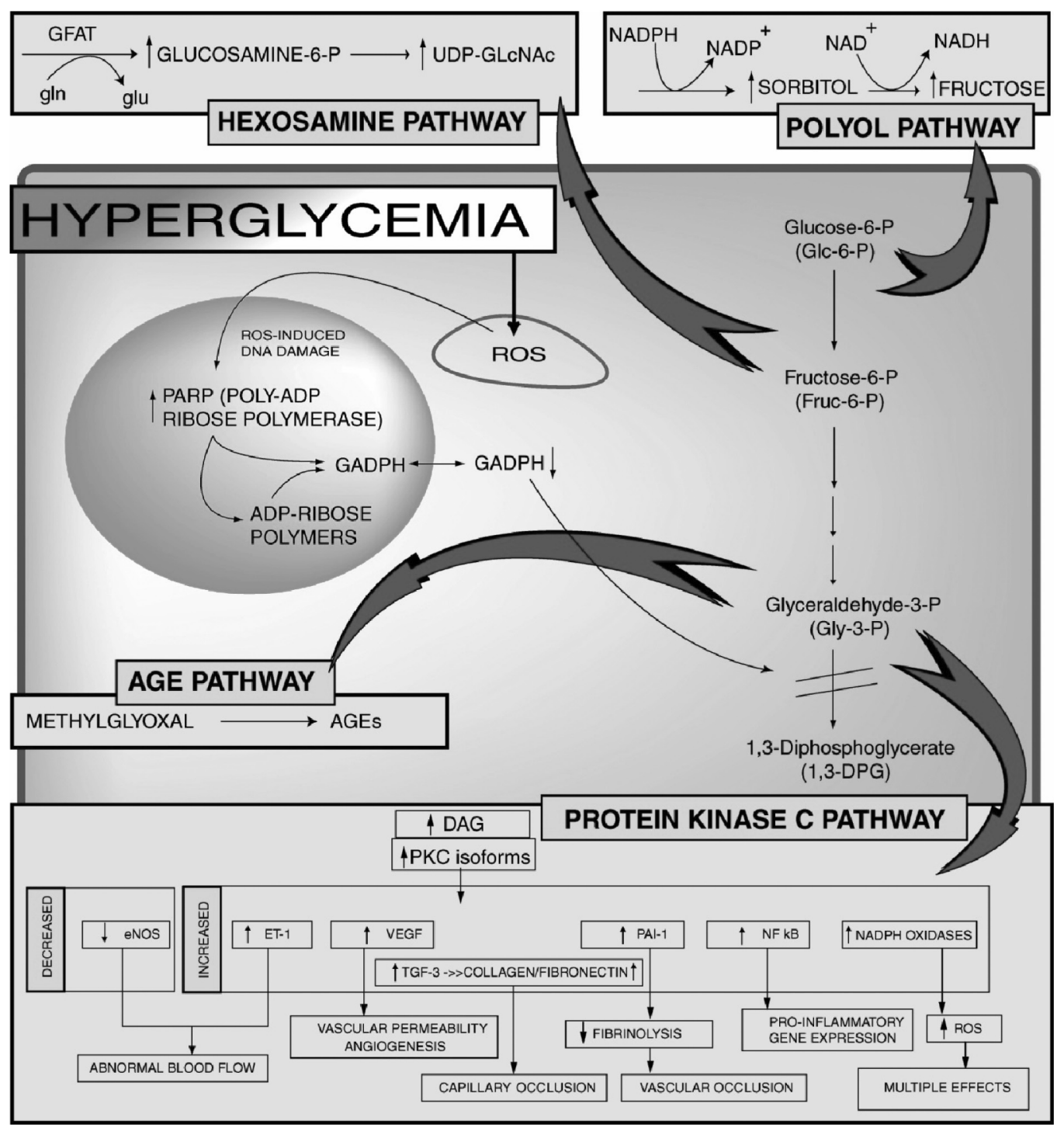

Figure 2 Mechanisms by which hyperglycemia induces mitochondrial overproduction of superoxide and activates 4 major pathways of hyperglycemic damage. 11,27 Copyright @ 2005 American Diabetes Association from Diabetes. 2005;54:1615-1625. ${ }^{27}$ Adapted with permission from the American Diabetes Association.

contribution of postprandial hyperglycemia to $\mathrm{HbA}_{1 \mathrm{c}}$ is greater at $\mathrm{HbA}_{1 \mathrm{c}}$ levels that are closer to 7\%. The ADA recommends that individuals who have preprandial glucose values within target, but have $\mathrm{HbA}_{1 \mathrm{c}}$ values above target, should monitor PPG 1 to 2 hours after the start of a meal. Treatment aimed at reducing PPG values to $<10 \mathrm{mmol} / \mathrm{L}(<180 \mathrm{mg} / \mathrm{dL})$ will likely lower $\mathrm{HbA}_{1 \mathrm{c}}$ and may improve outcomes. ${ }^{4}$

The International Diabetes Federation (IDF) recommends that patients with diabetes manage their $\mathrm{HbA}_{1 \mathrm{c}}$ levels to be $<6.5 \%$ by addressing both FPG and PPG. The guidelines recommend that PPG levels not exceed $7.8 \mathrm{mmol} / \mathrm{L}(140 \mathrm{mg} / \mathrm{dL})$ during the 2 hours postmeal. The frequency of self-monitoring to track PPG levels should be planned on an individual basis. ${ }^{36}$ AACE guidelines are similar to those of the IDF, suggesting $\mathrm{HbA}_{1 \mathrm{c}} \leq 6.5 \%, \mathrm{FPG}$
$<6 \mathrm{mmol} / \mathrm{L}(<110 \mathrm{mg} / \mathrm{dL})$, and 2-hour PPG $<7.8 \mathrm{mmol} / \mathrm{L}$ $(<140 \mathrm{mg} / \mathrm{dL})^{5}$

\section{Treatment considerations}

\section{Nonpharmacologic interventions}

Lifestyle management, including medical nutrition therapy (well-balanced diet), physical activity, and weight control, is recommended for all patients with type 2 diabetes. Decreases in $\mathrm{HbA}_{1 \mathrm{c}}$ of approximately $1 \%$ to $2 \%$ have been demonstrated in randomized controlled clinical trials and observational studies evaluating medical nutrition therapy. ${ }^{37}$ Of note, a recent systematic review and analysis by Boling et $\mathrm{al}^{38}$ echoed previous suggestions that low-carbohydrate (ie, $\leq 40 \%$ energy from carbohydrates), rather than "well-balanced," diets lead to better glycemic control $\left(\mathrm{HbA}_{1 \mathrm{c}}\right.$ decreases of $-0.9 \%$ 
to $-1.5 \%$ ) and may be the most efficacious dietary strategy for reducing obesity-related metabolic disease complications. Similarly, a meta-analysis by Barclay et $\mathrm{al}^{39}$ indicated that low glycemic index and glycemic load diets result in reduced risk for type 2 diabetes and heart disease. The most recent and notable example of the advantages of weight loss, conferred by increased physical activity and low-calorie/low-fat diets, ${ }^{40}$ are results from the 10-year follow-up of the Diabetes Prevention Program (DPP) Outcomes Study. ${ }^{41}$ This follow-up, prospective analysis included 2766 patients at high risk for developing type 2 diabetes from the initial DPP trial who received standard medical information regarding health risks and type 2 diabetes and placebo, metformin, or intensive lifestyle intervention (for details, consult the published description of the latter group $\left.{ }^{40}\right)$. The most significant findings of this study were that the placebo-adjusted incidences of a type 2 diabetes diagnosis at 10 years showed $34 \%$ and $18 \%$ reductions for the intensive lifestyle intervention and metformin groups, respectively. ${ }^{41}$ Interestingly, while patients in the lifestyle intervention and metformin groups tended to lose weight initially, mean weight of the 3 treatment groups tended to converge at 10 years, though at a range of 0 to $-2.5 \mathrm{~kg}$ change from baseline for all groups. ${ }^{41}$ However, clinicians clearly recognize that lifestyle interventions in most patients are largely ineffective without intensive supervision because it is difficult for most patients to change their lifestyle or maintain positive lifestyle changes. It has been shown that patients with higher perceived and actual risks of developing diabetes did not intend to adopt healthier lifestyle behaviors more readily than those with lower perceived and actual risks, ${ }^{42}$ though if followed closely with physician monitoring and clinical support, patients can indeed reap the benefits (eg, risk reduction of developing diabetes) of such alterations. ${ }^{39-41,43}$ Unfortunately, intensive treatment approaches are costly ${ }^{44,45}$ making them unpopular amidst the current economic crises worldwide and ever rising health care costs in the United States. Some efforts to reduce costs by using community resources or motivational techniques have shown promising results, ${ }^{46,47}$ but are far from large-scale implementation.

\section{Surgical intervention}

Obesity, superimposed on a genetic $\beta$-cell defect, is the main cause for the increased prevalence of type 2 diabetes. ${ }^{48}$ Bariatric surgery is a growing weight loss option for obese people who have failed lifestyle and diet pill interventions. The National Institutes of Health (NIH) guidelines require bariatric surgery candidates to have a body mass index (BMI) $>40 \mathrm{~kg} / \mathrm{m}^{2}$ (severe obesity) or a BMI between 35 and
$39.9 \mathrm{~kg} / \mathrm{m}^{2}$ with a serious obesity-related health problem such as type 2 diabetes, coronary heart disease, or severe sleep apnea. ${ }^{49}$ This is unconscionable considering some healthcare providers believe that the NIH guideline should be less restrictive, given the considerable health and cost benefits of bariatric surgery. ${ }^{50}$

Bariatric surgery has dramatic effects on glycemic control. For example, in a randomized controlled trial with 60 obese patients (BMI $>30$ and $<40 \mathrm{~kg} / \mathrm{m}^{2}$ ) with type 2 diabetes $<2$ years, half the patients had laparoscopic adjustable gastric banding with conventional diabetes care; the other half had conventional diabetes therapy with lifestyle changes. Among patients who completed the 2-year followup, $73 \%$ in the surgical group versus $13 \%$ in the control group achieved remission of type 2 diabetes. ${ }^{51}$ A 10 -year study comparing conventional (nonsurgical) treatment with bariatric surgery showed recovery from diabetes in $72 \%$ of patients in the bariatric surgical group, compared with $21 \%$ in the nonsurgical group after 2 years. ${ }^{52}$ Furthermore, a cost-analysis study indicates that there is a return on investment in 2 to 5 years postsurgery with respect to the costs associated with comorbidities in morbidly obese patients, including those with type 2 diabetes, CAD, hypertension, and sleep apnea. ${ }^{50}$ While this strategy is gaining further popularity among patients with $\mathrm{BMI} \geq 35 \mathrm{~kg} / \mathrm{m}^{2}$, long-term studies among the dysglycemic subpopulation are needed to ascertain whether this strategy can be applied universally to obese patients with postprandial hyperglycemia.

\section{Pharmacologic interventions}

The classes of drugs for the treatment of type 2 diabetes that primarily target postprandial hyperglycemia are summarized in Table 2.6,11,53 The 2 newest classes of antidiabetic agents - dipeptidyl peptidase-4 (DPP-4) inhibitors and glucagon-like peptide-1 (GLP-1) analogs - are incretin-based therapies. The incretin hormones, GLP-1 and glucose-dependent insulinotropic polypeptide (GIP), are released from the small intestine during absorption of meals and increase pancreatic secretion of insulin. ${ }^{54}$ GLP-1, but not GIP, suppresses glucagon release from the pancreatic $\alpha$-cells. In type 2 diabetes, incretin hormone function is impaired, ${ }^{54}$ resulting in less insulin release and more glucagon secretion after meals. ${ }^{55}$ More glucose enters the circulation, but there is less efficient glucose removal, higher plasma glucose levels, and hence, acute oxidative stress. ${ }^{22,55}$ Disease-related complications associated with oxidative stress may be reduced with agents that target postprandial hyperglycemia. 


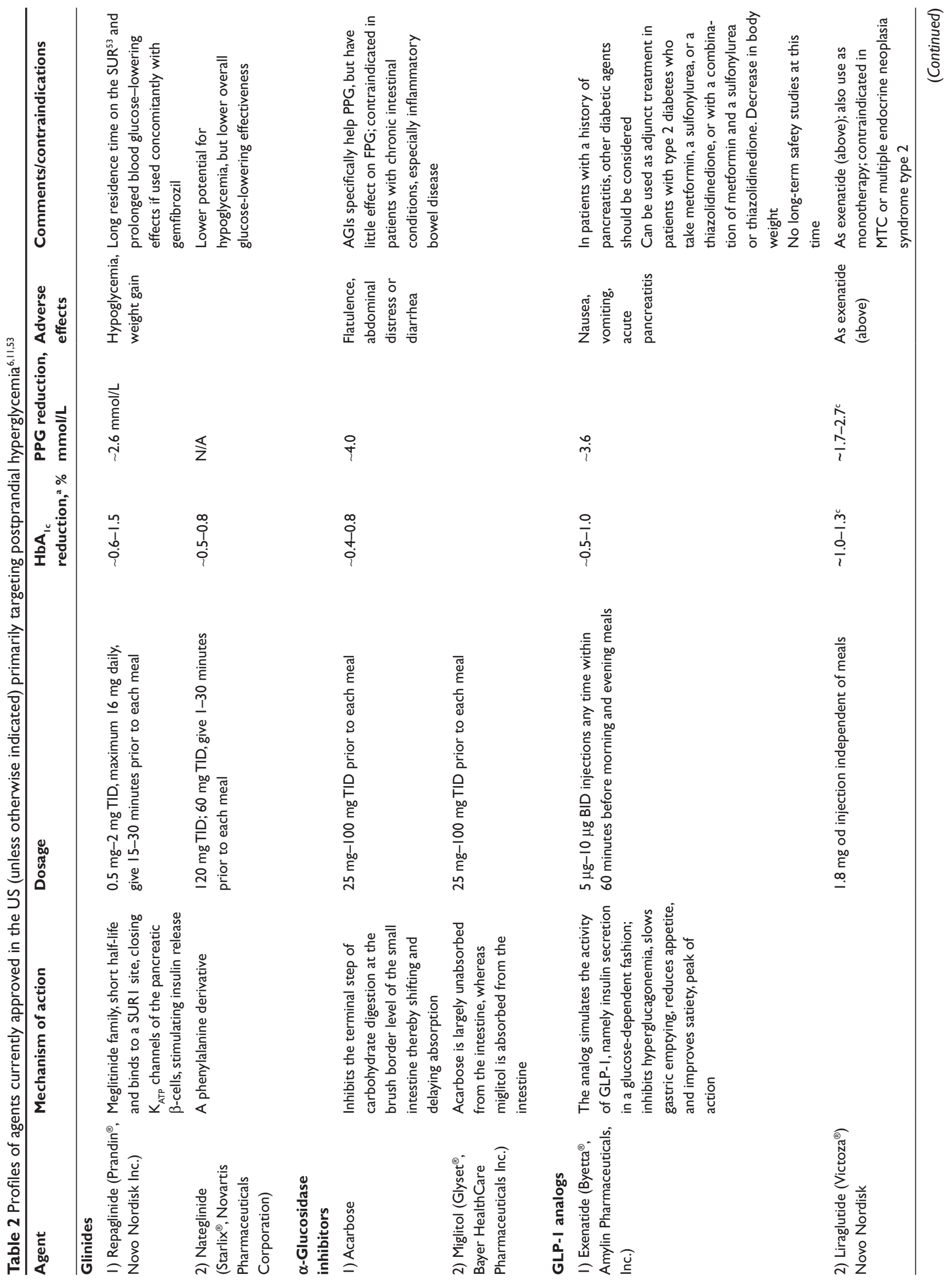




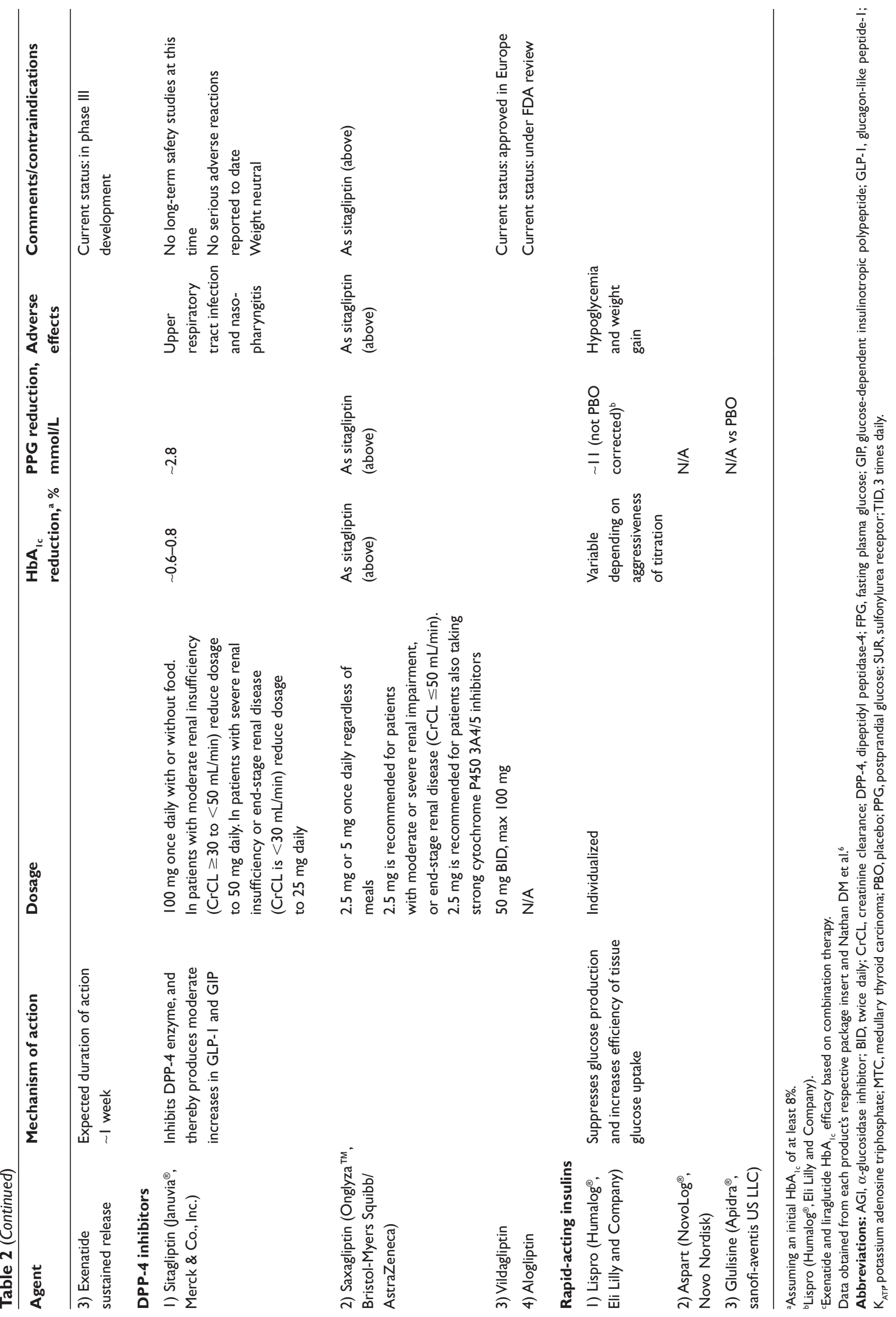




\section{GLP-I analogs}

Endogenous GLP-1 is rapidly cleared (1-2 minutes) by the enzyme DPP-4; therefore, the natural form is not practical as a therapeutic intervention in type 2 diabetes management. ${ }^{56}$ Injectable GLP-1 analogs are resistant to DPP-4 and thus, have a longer half-life than endogenous GLP-1. GLP-1 analogs increase glucose-dependent insulin secretion and decrease glucagon secretion, leading to PPG control, delayed gastric emptying, and increased satiety, potentially leading to weight loss. Exenatide (Byetta ${ }^{\circledR}$, Amylin Pharmaceuticals, Inc.) and liraglutide $\left(\right.$ Victoza $^{\circledR}$; Novo Nordisk) are injected twice daily and once daily, respectively. Their use in combination lowers $\mathrm{HbA}_{1 \mathrm{c}}$ by approximately $0.5 \%$ to $1.0 \%{ }^{6,57}$ Both agents are approved for use in combination with metformin, a sulfonylurea (SU), and/or a thiazolidinedione (TZD); liraglutide is also available as monotherapy in the United States. ${ }^{6,57}$ Both agents are associated with gastrointestinal (GI) side effects, including diarrhea, vomiting, and nausea and there is also an association with acute pancreatitis. ${ }^{6,57}$ Therefore, the Food and Drug Administration recommends that in a patient with diabetes who has a history of pancreatitis, other antidiabetic agents should be considered. ${ }^{57,58}$ For liraglutide, the US prescribing information includes a boxed warning for the risk of thyroid C-cell tumors. ${ }^{57}$ A sustained-release form of exenatide, with duration of up to one week is currently in late-phase development. ${ }^{59,60}$

\section{DPP-4 inhibitors}

The DPP-4 inhibitors sitagliptin and saxagliptin were approved in 2006 and 2009, respectively. Vildagliptin, another DPP-4 inhibitor, is currently approved outside the United States. DPP4 inhibitors, like GLP-1 analogs, mechanistically decrease PPG and have a low propensity for hypoglycemia or weight gain. ${ }^{61-63}$ Alogliptin, dutogliptin, and linagliptin are other DPP-4 inhibitors in various stages of development. These DPP-4 inhibitors have been studied as monotherapy as well as in combination with metformin, SUs, and TZDs. DPP-4 inhibitors have fewer GI side effects than GLP-1 analogs. ${ }^{61,63}$

\section{Rapid-acting insulins}

Rapid-acting insulins (lispro, aspart, or glulisine) improve PPG when administered before a meal. ${ }^{29,64,65}$ An alternative would be pre-breakfast and pre-dinner premix insulins containing a rapidacting insulin and a long-acting insulin. ${ }^{66}$ These latter insulin regimens, however, are less flexible and are associated with greater risk of hypoglycemia than rapid-acting insulin regimens. ${ }^{66}$

\section{Guideline update}

In 2009, the AACE released a new treatment algorithm. While there were no changes to the placement of insulin in the algorithm (ie, last line of therapy after oral antidiabetic drug use), the new recommendations advocate the early use of the incretin-based therapies GLP-1 analogues and DPP-4 inhibitors. ${ }^{67}$ More specifically, incretin-based therapies are recommended as monotherapy for patients with $\mathrm{HbA}_{1 \mathrm{c}} 6.5 \%$ to $7.5 \%$, which most closely corresponds to the $\mathrm{HbA}_{1 \mathrm{c}}$ range previously identified to be most impacted by PPG targeting. 7,28

\section{Conclusions}

Substantial evidence has accumulated indicating that chronic hyperglycemia is a risk factor for micro- and macrovascular disease. Observational studies indicate that isolated postprandial hyperglycemia increases CV mortality. Various antihyperglycemic agents now exist that preferentially target postprandial hyperglycemia (meglitinides, rapid-acting insulin analogs, GLP-1 agonists, and DPP-4 inhibitors) and afford physicians a choice of treatment options that can now be based on individual patient profiles. Controlling and achieving target goals early in the course of diabetes has been shown to provide better outcomes in terms of CV risk. Postprandial glucose should be normalized along with FPG to achieve the currently recommended goal of $\mathrm{HbA}_{10}$ $<7 \%$. As reflected in recent trials, a less intense goal may be needed for certain subpopulations of patients with diabetes who have a history of severe CVD, severe hypoglycemia, advanced age, or advanced microvascular or macrovascular complications. Target levels of glucose control should be individualized by focusing on both FPG and PPG and by optimizing other risk factors of CVD, including high blood pressure, hyperlipidemia, obesity, smoking, and poor exercise and dietary habits.

\section{Acknowledgments}

Technical and editorial assistance for this manuscript was provided by Trina Ricci, PhD, of Quintiles.

\section{Funding source}

Technical and editorial assistance was funded by BristolMyers Squibb and AstraZeneca. The authors received no remuneration and are solely responsible for the content.

\section{Disclosures}

Dr Aryangat has nothing to declare. Dr Gerich has served on advisory boards and/or speakers' bureaus for, and has received honoraria or consulting fees from, Amylin Pharmaceuticals, AstraZeneca, Bristol-Myers Squibb, Centocor, Daiichi Sankyo, Eisai, Elixir, Forest Laboratories, GlaxoSmithKline, 
Johnson \& Johnson, Kowa, LifeScan, MannKind Corporation, Merck, Novartis, Novo Nordisk, Pfizer, sanofi-aventis, and Sirtris Pharmaceuticals. Dr Gerich has received grant support from Boehringer Ingelheim, Bristol-Myers Squibb, Daiichi Sankyo, GlaxoSmithKline, Kowa, Novartis, Novo Nordisk, Pfizer, sanofi-aventis, and Sirtris Pharmaceuticals. Dr Gerich has received grant support from Boehringer Ingelheim, Bristol-Myers Squlbb, Daiichi Sankyo, GlaxoSmithKline, Kowa, Novartis, Novo Nordisk, Pfizer, sanofiaventis, and Takeda, and served on the rimonabant data safety monitoring board for sanofi-aventis.

\section{References}

1. UK Prospective Diabetes Study (UKPDS) Group. Intensive bloodglucose control with sulphonylureas or insulin compared with conventional treatment and risk of complications in patients with type 2 diabetes (UKPDS 33). Lancet. 1998;352:837-853.

2. Patel A, MacMahon S, Chalmers J, et al; for the ADVANCE Collaborative Group. Intensive blood glucose control and vascular outcomes in patients with type 2 diabetes. N Engl J Med. 2008;358:2560-2572.

3. The Writing Team for the Diabetes Control and Complications Trial/ Epidemiology of Diabetes Interventions and Complications Research Group. Effect of intensive therapy on the microvascular complications of type 1 diabetes mellitus. JAMA. 2002;287:2563-2569.

4. American Diabetes Association. Standards of medical care in diabetes2009. Diabetes Care. 2009;32(Suppl 1):S13-S61.

5. Rodbard HW, Blonde L, Braithwaite S, et al. American Association of Clinical Endocrinologists medical guidelines for clinical practice for the management of diabetes mellitus. Endocr Pract. 2007;13(suppl 1):1-68.

6. Nathan DM, Buse JB, Davidson MB, et al. Medical management of hyperglycemia in type 2 diabetes: a consensus algorithm for the initiation and adjustment of therapy: a consensus statement of the American Diabetes Association and the European Association for the Study of Diabetes. Diabetes Care. 2009;32:193-203.

7. Woerle HJ, Neumann C, Zschau S, et al. Impact of fasting and postprandial glycemia on overall glycemic control in type 2 diabetes: importance of postprandial glycemia to achieve target $\mathrm{HbA}_{1 \mathrm{c}}$ levels. Diabetes Res Clin Pract. 2007;77:280-285.

8. Malmberg K, Rydén L, Wedel H, et al; for the DIGAMI 2 Investigators. Intense metabolic control by means of insulin in patients with diabetes mellitus and acute myocardial infarction (DIGAMI 2): effects on mortality and morbidity. Eur Heart J. 2005;26:650-661.

9. Dale AC, Vatten LJ, Nilsen TI, Midthjell K, Wiseth R. Secular decline in mortality from coronary heart disease in adults with diabetes mellitus: cohort study. BMJ. 2008;337:a236.

10. Yusuf S, Hawken S, Ônpuu S, et al; for the INTERHEART Study Investigators. Effect of potentially modifiable risk factors associated with myocardial infarction in 52 countries (the INTERHEART study): case-control study. Lancet. 2004;364:937-952.

11. Gerich JE. Clinical significance, pathogenesis, and management of postprandial hyperglycemia. Arch Intern Med. 2003;163:1306-1316.

12. Cavalot F, Petrelli A, Traversa M, et al. Postprandial blood glucose is a stronger predictor of cardiovascular events than fasting blood glucose in type 2 diabetes mellitus, particularly in women: lessons from the San Luigi Gonzaga Diabetes Study. J Clin Endocrinol Metab. 2006;91:813-819.

13. Tominaga M, Eguchi H, Manaka H, Igarashi K, Kato T, Sekikawa A; for the Funagata Diabetes Study. Impaired glucose tolerance is a risk factor for cardiovascular disease, but not impaired fasting glucose. Diabetes Care. 1999;22:920-924.

14. Gerstein HC, Miller ME, Byington RP, et al; for the Action to Control Cardiovascular Risk in Diabetes Study Group. Effects of intensive glucose lowering in type 2 diabetes. $N$ Engl J Med. 2008;358:2545-2559.
15. Holman RR, Paul SK, Bethel MA, Matthews DR, Neil HA. 10-year follow-up of intensive glucose control in type 2 diabetes. NEngl J Med. 2008;359:1577-1589.

16. Nathan DM, Cleary PA, Backlund JY, et al; for the Diabetes Control and Complications Trial/Epidemiology of Diabetes Interventions and Complications (DCCT/EDIC) Study Research Group. Intensive diabetes treatment and cardiovascular disease in patients with type 1 diabetes. N Engl J Med. 2005;353:2643-2653.

17. Duckworth W, Abraira C, Moritz T, et al; for the VADT Investigators. Glucose control and vascular complications in veterans with type 2 diabetes. N Engl J Med. 2009;360:129-139.

18. Skyler JS, Bergenstal R, Bonow RO, et al. Intensive glycemic control and the prevention of cardiovascular events: implications of the ACCORD, ADVANCE, and VA diabetes trials: a position statement of the American Diabetes Association and a scientific statement of the American College of Cardiology Foundation and the American Heart Association. Diabetes Care. 2009;32:187-192.

19. Monnier L, Mas E, Ginet C, et al. Activation of oxidative stress by acute glucose fluctuations compared with sustained chronic hyperglycemia in patients with type 2 diabetes. JAMA. 2006;295:1681-1687.

20. Ceriello A, Esposito K, Piconi L, et al. Oscillating glucose is more deleterious to endothelial function and oxidative stress than mean glucose in normal and type 2 diabetic patients. Diabetes. 2008;57:1349-1354.

21. Beckman JA, Goldfine AB, Gordon MB, Creager MA. Ascorbate restores endothelium-dependent vasodilation impaired by acute hyperglycemia in humans. Circulation. 2001;103:1618-1623.

22. Monnier L, Colette C. Glycemic variability: should we and can we prevent it? Diabetes Care. 2008;31(suppl 2):S150-S154.

23. Shimabukuro M, Higa N, Chinen I, Yamakawa K, Takasu N. Effects of a single administration of acarbose on postprandial glucose excursion and endothelial dysfunction in type 2 diabetic patients: a randomized crossover study. J Clin Endocrinol Metab. 2006;91:837-842.

24. Weinbaum S, Zhang X, Han Y, Vink H, Cowin SC. Mechanotransduction and flow across the endothelial glycocalyx. Proc Natl Acad Sci U SA. 2003;100:7988-7995.

25. Noble MI, Drake-Holland AJ, Vink H. Hypothesis: arterial glycocalyx dysfunction is the first step in the atherothrombotic process. QJM. 2008;101:513-518.

26. Nieuwdorp M, Van Haeften TW, Gouverneur MC, et al. Loss of endothelial glycocalyx during acute hyperglycemia coincides with endothelial dysfunction and coagulation activation in vivo. Diabetes. 2006;55:480-486.

27. Brownlee M. The pathobiology of diabetic complications: a unifying mechanism. Diabetes. 2005;54:1615-1625.

28. Monnier L, Lapinski H, Colette C. Contributions of fasting and postprandial plasma glucose increments to the overall diurnal hyperglycemia of type 2 diabetic patients: variations with increasing levels of $\mathrm{HbA}_{1 \mathrm{c}}$. Diabetes Care. 2003;26:881-885.

29. Holman RR, Farmer AJ, Davies MJ, et al. Three-year efficacy of complex insulin regimens in type 2 diabetes. $N$ Engl J Med. 2009;361:1736-1747.

30. Chiasson JL, Josse RG, Gomis R, Hanefeld M, Karasik A, Laakso M, for the STOP-NIDDM Trial Research Group. Acarbose treatment and the risk of cardiovascular disease and hypertension in patients with impaired glucose tolerance: the STOP-NIDDM trial. JAMA. 2003;290:486-494.

31. Esposito K, Ciotola M, Carleo D, et al. Post-meal glucose peaks at home associate with carotid intima-media thickness in type 2 diabetes. $J$ Clin Endocrinol Metab. 2008;93:1345-1350.

32. Mita T, Watada H, Shimizu T, et al. Nateglinide reduces carotid intimamedia thickening in type 2 diabetic patients under good glycemic control. Arterioscler Thromb Vasc Biol. 2007;27:2456-2462.

33. Hanefeld M, Chiasson JL, Koehler C, Henkel E, Schaper F, TemelkovaKurktschiev T. Acarbose slows progression of intima-media thickness of the carotid arteries in subjects with impaired glucose tolerance. Stroke. 2004;35:1073-1078.

34. Iijima R, Nakajima R, Sugi K, Nakamura M. Improvement of postprandial hyperglycemia has a positive impact on epicardial flow of entire coronary tree in acute coronary syndromes patients. Circ J. 2007;71:1079-1085. 
35. Scognamiglio R, Negut C, De Kreutzenberg SV, Tiengo A, Avogaro A. Postprandial myocardial perfusion in healthy subjects and in type 2 diabetic patients. Circulation. 2005;112:179-184.

36. International Diabetes Federation. Guideline for management of postmeal glucose. Brussels, Belgium: International Diabetes Federation; 2007. http://www.idf.org/webdata/docs/Guideline_PMG_final.pdf. Accessed November 24, 2009.

37. Pastors JG, Warshaw H, Daly A, Franz M, Kulkarni K. The evidence for the effectiveness of medical nutrition therapy in diabetes management Diabetes Care. 2002;25:608-613.

38. Boling CL, Westman EC, Yancy WS Jr. Carbohydrate-restricted diets for obesity and related diseases: an update. Curr Atheroscler Rep. 2009;11:462-469.

39. Barclay AW, Petocz P, Millan-Price J, et al. Glycemic index, glycemic load, and chronic disease risk-a meta-analysis of observational studies. Am J Clin Nutr. 2008;87:627-637.

40. Diabetes Prevention Program Research Group. The Diabetes Prevention Program (DPP): description of lifestyle intervention. Diabetes Care. 2002;25:2165-2171.

41. Diabetes Prevention Program Research Group, Knowler WC, Fowler SE, Hamman RF, et al. 10-year follow-up of diabetes incidence and weight loss in the Diabetes Prevention Program Outcomes Study. Lancet. 2009;374:1677-1686.

42. Hivert MF, Warner AS, Shrader P, Grant RW, Meigs JB. Diabetes risk perception and intention to adopt healthy lifestyles among primary care patients. Diabetes Care. 2009;32:1820-1822.

43. Ratner R, Goldberg R, Haffner S, et al. Impact of intensive lifestyle and metformin therapy on cardiovascular disease risk factors in the diabetes prevention program. Diabetes Care. 2005;28:888-894.

44. Diabetes Prevention Program. Within-trial cost-effectiveness of lifestyle intervention or metformin for the primary prevention of type 2 diabetes. Diabetes Care. 2003;26:2518-2523.

45. Lindgren P, Lindstrom J, Tuomilehto J, et al. Lifestyle intervention to prevent diabetes in men and women with impaired glucose tolerance is cost-effective. Int J Technol Assess Health Care. 2007;23:177-183.

46. Ackermann RT, Finch EA, Brizendine E, Zhou H, Marrero DG. Translating the Diabetes Prevention Program into the community. The DEPLOY Pilot Study. Am J Prev Med. 2008;35:357-363.

47. Greaves CJ, Middlebrooke A, O'Loughlin L, et al. Motivational interviewing for modifying diabetes risk: a randomised controlled trial. Br J Gen Pract. 2008;58:535-540.

48. Romao I, Roth J. Genetic and environmental interactions in obesity and type 2 diabetes. $J$ Am Diet Assoc. 2008;108:S24-S28.

49. National Institute of Diabetes and Digestive and Kidney Diseases Bariatric surgery for severe obesity. Weight-Control Information Network Web site. NIH Publication No. 08-4006. http://win.niddk.nih. gov/publications/gastric.htm. Accessed November 24, 2009.

50. Crémieux P-Y, Buchwald H, Shikora SA, Ghosh A, Yang HE, Buessing M. A study on the economic impact of bariatric surgery. Am J Manag Care. 2008;14:589-596.

51. Dixon JB, O'Brien PE, Playfair J, et al. Adjustable gastric banding and conventional therapy for type 2 diabetes: a randomized controlled trial. JAMA. 2008;299:316-323.

52. Sjöström L, Lindroos A-K, Peltonen M, et al; for the Swedish Obese Subjects Study Scientific Group. Lifestyle, diabetes, and cardiovascular risk factors 10 years after bariatric surgery. $N$ Engl $J$ Med. 2004;351:2683-2693.
53. Hu S, Wang S, Fanelli B, et al. Pancreatic $\beta$-cell KATP channel activity and membrane-binding studies with nateglinide: a comparison with sulfonylureas and repaglinide. J Pharmacol Exp Ther. 2000;293:444-452.

54. Drucker DJ, Nauck MA. The incretin system: glucagon-like peptide-1 receptor agonists and dipeptidyl peptidase- 4 inhibitors in type 2 diabetes. Lancet. 2006;368:1696-1705.

55. Mitrakou A, Kelley D, Veneman T, et al. Contribution of abnormal muscle and liver glucose metabolism to postprandial hyperglycemia in NIDDM. Diabetes. 1990;39:1381-1390.

56. Drucker DJ. Enhancing incretin action for the treatment of type 2 diabetes. Diabetes Care. 2003;26:2929-2940.

57. Victoza [package insert]. Bagsvaerd, Denmark: Novo Nordisk A/S; January 2010

58. US Food and Drug Administration/Center for Drug Evaluation and Research. Exenatide (marketed as Byetta)-Healthcare professional sheet text version (8/2008). FDA Web site. Updated August 18, 2008. http://www.fda.gov/Drugs/DrugSafety/ PostmarketDrugSafetyInformationforPatientsandProviders/ ucm124713.htm. Accessed November 24, 2009.

59. Vilsbøll T, Zdravkovic M, Le-Thi T, et al. Liraglutide, a long-acting human glucagon-like peptide-1 analog, given as monotherapy significantly improves glycemic control and lowers body weight without risk of hypoglycemia in patients with type 2 diabetes. Diabetes Care. 2007;30:1608-1610.

60. Nauck MA, Hompesch M, Filipczak R, Le TD, Zdravkovic M, Gumprecht J; for the NN2211-1499 Study Group. Five weeks of treatment with the GLP-1 analogue liraglutide improves glycaemic control and lowers body weight in subjects with type 2 diabetes. Exp Clin Endocrinol Diabetes. 2006;114:417-423.

61. Rosenstock J, Sankoh S, List JF. Glucose-lowering activity of the dipeptidyl peptidase-4 inhibitor saxagliptin in drug-naive patients with type 2 diabetes. Diabetes Obes Metab. 2008;10:376-386.

62. Aschner P, Kipnes MS, Lunceford JK, Sanchez M, Mickel C, WilliamsHerman DE; for the Sitagliptin Study 021 Group. Effect of the dipeptidyl peptidase-4 inhibitor sitagliptin as monotherapy on glycemic control in patients with type 2 diabetes. Diabetes Care. 2006;29:2632-2637.

63. Pi-Sunyer FX, Schweizer A, Mills D, Dejager S. Efficacy and tolerability of vildagliptin monotherapy in drug-naive patients with type 2 diabetes. Diabetes Res Clin Pract. 2007;76:132-138.

64. Gough SCL. A review of human and analogue insulin trials. Diabetes Res Clin Pract. 2007;77:1-15.

65. Giugliano D, Ceriello A, Razzoli E, Esposito K. Defining the role of insulin lispro in the management of postprandial hyperglycaemia in patients with type 2 diabetes mellitus. Clin Drug Investig. 2008; 28:199-210.

66. Ilag LL, Kerr L, Malone JK, Tan MH. Prandial premixed insulin analogue regimens versus basal insulin analogue regimens in the management of type 2 diabetes: an evidence-based comparison. Clin Ther. 2007;29:1254-1270

67. Rodbard HW, Jellinger PS, Davidson JA, et al. Statement by an American Association of Clinical Endocrinologists/American College of Endocrinology Consensus Panel on type 2 diabetes mellitus: an algorithm for glycemic control. Endocr Pract. 2009;15:541-559.
Vascular Health and Risk Management

\section{Publish your work in this journal}

Vascular Health and Risk Management is an international, peerreviewed journal of therapeutics and risk management, focusing on concise rapid reporting of clinical studies on the processes involved in the maintenance of vascular health; the monitoring, prevention and treatment of vascular disease and its sequelae; and the involvement of

\section{Dovepress}

metabolic disorders, particularly diabetes. This journal is indexed on PubMed Central and MedLine. The manuscript management system is completely online and includes a very quick and fair peer-review system, which is all easy to use. Visit http://www.dovepress.com/ testimonials.php to read real quotes from published authors. 